\title{
Complementary Feeding Knowledge and Practices of Caregivers in Orphanages Improved after Nutrition Education Intervention in Ibadan, Nigeria
}

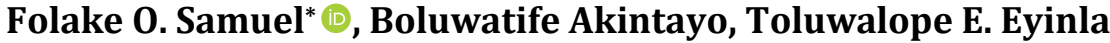 \\ Department of Human Nutrition and Dietetics, University of Ibadan, Ibadan, Nigeria \\ Email: *samuelfolake@gmail.com
}

How to cite this paper: Samuel, F.O., Akintayo, B. and Eyinla, T.E. (2021) Complementary Feeding Knowledge and Practices of Caregivers in Orphanages Improved after Nutrition Education Intervention in Ibadan, Nigeria. Open Journal of Nursing, 11, 642-652.

https://doi.org/10.4236/ojn.2021.117054

Received: June 7, 2021

Accepted: July 27, 2021

Published: July 30, 2021

Copyright $\odot 2021$ by author(s) and Scientific Research Publishing Inc. This work is licensed under the Creative Commons Attribution International License (CC BY 4.0).

http://creativecommons.org/licenses/by/4.0/

\begin{abstract}
Malnutrition among under-5 children has been linked to inadequate complementary feeding practices. Children living without permanent parents have also been proven to have a higher risk of malnutrition, which puts their growth and development in danger. In this study, an impact evaluation of nutrition education was carried out on the knowledge and practice of complementary feeding among caregivers in orphanages. This quasi-experimental study was conducted in selected orphanage homes located within Ibadan, southwestern Nigeria. A purposive sampling technique was employed to select 50 caregivers from 8 orphanage homes. Data was collected using an adapted interviewer administered at baseline and post-intervention. The key results showed that those who had good knowledge of complementary feeding practices increased from $68.1 \%$ to $79.9 \%$ at baseline and post-intervention respectively. The WHO complementary feeding indicators that were used to measure the practice revealed that $37.5 \%$ met the minimum meal frequency (MMF), 52.5\% met the minimum dietary diversity (MDD) and 35\% met the minimum adequate diet (MAD) at baseline, which increased to $62.5 \%, 80 \%$ and $60 \%$ respectively after intervention. Conclusively, this study revealed that nutrition education improved the complementary feeding knowledge and practice of caregivers. It is recommended that such nutrition education should be introduced to new caregivers and could also be converted into policy actions at a national level.
\end{abstract}




\section{Keywords}

Nutrition Education, Caregivers, Orphanages, Complementary Feeding

\section{Introduction}

Complementary feeding as described by World Health Organization (WHO) refers to the process of introducing other foods and liquids when breast milk alone is no longer sufficient to meet the nutritional requirements of infants. It typically covers the period from 6 to 24 months of age [1]. At about 6 months of age, infants and young children are at an increased risk of malnutrition because breast milk is no longer sufficient to meet all their nutritional requirements and complementary feeding should be started [2]. Adequate nutrition during infancy and early childhood is essential to ensure the growth, health, and development of children to their full potential [3]. Improper feeding practices include both the quality and quantity of foods offered to young children as well as the timing of their introduction [4]. The prevalence of malnutrition and micronutrient deficiency increases quickly under five children because of their swift growth and development; therefore, the deficiency of these nutrients undermines the normal growth and development [5]. According to the 2018 National Demographic Health survey, $22 \%$ of under-5 children are underweight, $7 \%$ are wasted and $37 \%$ are stunted, which makes under-nutrition a present public health problem in Nigeria [6]. With few exceptions, children without parents are deprived of many of the basic rights such as food, shelter, education, and a family environment [7]. An orphanage is an institution dedicated to the care and upbringing of children who have lost their parents [8]. Orphans are vulnerable in any socio-economic setting as they are deprived of one or both of their primary caregivers and are some of the most under-privileged children in the world [3]. There is the need for parental (or caregivers) education, sound and correct child rearing practices and in particular advice on how, when, why and with what to feed the child from what is easily available in the household. Poor nutrition knowledge and practices of mothers or child caregivers have been found to be linked to child malnutrition [9]. A study carried out in some selected orphanage homes in north central Nigeria recorded high prevalence of malnutrition among the under-five children and this was linked to dietary deficiencies of some macro-and micro nutrients, faulty feeding practices, low socio-economic status, and low nutrition education of caregivers [6]. In a recent study carried out in India, nutrition education was recorded to significantly improve the nutrition knowledge of caregivers of infants [10]. Studies carried out in Nigerian orphanages have focused on the nutritional status of the children [11] [12] and have paid little or no attention to the caregivers' feeding knowledge and practices which is an important determinant of the nutritional and health outcomes of these children. 
There is also a dearth of research/information on complementary feeding practices of caregivers in orphanage homes. This study therefore, assessed the complementary feeding knowledge and practices of caregivers in orphanage homes, designed and implemented a nutrition education intervention program and further evaluated the impact of this intervention.

\section{Methodology}

\subsection{Study Area}

This study was carried out in 3 out of the 5 Local Government Areas (LGAs) in Ibadan, the capital city of Oyo state, Southwestern Nigeria.

\subsection{Study Design}

A quasi-experimental study design was adopted.

\subsection{Study Population}

Selection of the orphanages across the 3 randomly selected LGAs was purposive and based on firstly the willingness of the orphanages to participate and secondly the availability of children between the ages 6 to 24 months old in each orphanage. In all, 8 orphanages agreed to participate in the study. In each participating orphanage home, caregivers who were actively involved in cooking, feeding and taking care of children between 6 - 24 months were assessed at baseline; a total of 50 eligible caregivers. Of these, only 26 were available for the nutrition education intervention and 24 available for post-intervention assessment after two weeks. Complementary feeding of 40 children between 6 - 24 months of age who resided in the orphanages was also assessed.

\subsection{Data Collection}

A semi-structured, pre-tested interviewer-administered questionnaire adapted from a validated KAP questionnaire [13] was used to collect data on complementary feeding knowledge and practices of caregivers. A descriptive 24-hour diet recall was used in addition to the orphanage's food timetable for young children (6 - 24 months to generate the food groups consumed by the children in 24 hours. The caregivers' questionnaire was administered thrice: first at baseline, then immediately after intervention and finally, two weeks after intervention. Data was collected on the caregivers' knowledge on the introduction of solid, semi-solid and soft foods, frequency of feeding, diet diversity, consistency of the food, consumption of vitamin A rich fruits and other fruits and vegetables. A caregiver was scored " 1 " for every question answered correctly and "0" for a question wrongly answered with 30 being the highest attainable score, while $75 \%$ was used as the cut-off point. Any score above $75 \%$ of the 30 questions ( $\geq 22.5$ ) were therefore classified as good knowledge and any score below was classified as poor knowledge. The complementary feeding practice of the caregivers in the orphanage was assessed according to selected indicators of the World Health 
Organization for infant and young child feeding namely, Minimum Meal Frequency, Minimum Dietary Diversity and Minimum Adequate Diet. Minimum meal frequency is the proportion of children who received complementary foods at least the minimum recommended number of times in the last 24 hours. A child was said to have taken "adequate" number of meals if he/she received at least the minimum frequency for appropriate complementary feeding (that is, 2 3 times for 6 - 8 months and 3 - 4 times for 9 - 11 months and 3 - 4 times for children aged $12-23$ months) in last 24 hours. For non-breastfed children, the minimum meal frequency was 4 meals in the last 24 hours. The minimum dietary diversity indicator was constructed using the WHO recommended cut-off point with a value of " 1 " if the child had consumed four or more groups of foods and " 0 " if less. The diet diversity was assessed by taking a descriptive 24-hour diet recall of all food the children ate in the past 24 hours including the snacks and beverage. The food group consumed by the child was derived from this data and used to calculate the Minimum Diet Diversity. The minimum adequate diet component was calculated using 6 food groups (excluding dairy products) and consumption of milk feeds (at least 2 cups) in the last 24 hours. The milk consumption that was used to calculate the Minimum Adequate Diet (MAD) for this study was at least 1 cup feeding for a non-breastfed child, so as to accommodate the respondent(s) that fed the children with 1 cup of milk in the last 24 hours. Data collection was carried out between May and July, 2016.

\subsection{Nutrition Education Intervention}

For the intervention, a one-day training session was carried out in the selected orphanages. Lectures, pictorial interactive session and demonstrations were used as nutrition education tools. A training manual which was adapted from the National counseling cards for infant and young child feeding was also used [14]. The pictorial interactive session featured pictures on 5 different cardboards with each cardboard having its own heading. The headings captured were: Introduction of Solid, semi-solid and Soft food starting at 6 months, Frequency of feeding, Diet diversity, feeding of non-Breastfed Children. All the pictures were explicitly discussed. The training therefore provided information on: Timely initiation of complementary foods, the specific quantity of food per age group, The frequency of feeding per age group and the consistency (thickness) of food given to a child. Others include the quality of the food that ensures adequate nutrition in a complementary food and the feeding of non-breastfed children.

A demonstration was used by the researchers/trainers to illustrate the inadequacy of breast milk after 6 months because some of the children in the orphanage home might be breastfed at a point. Four bottles of the same size were filled to different levels with water to indicate the space that nutrient from complementary food should fill in a 6- to 8-month-old child, 9- to 12-month old child and 12 - 24 months old child who is fed along with breast milk and a non-breastfed child. 


\subsection{Data Analysis}

Data was analyzed using IBM SPSS (version 20) and descriptive analysis was employed to calculate frequency and percentage. Paired t-test was used to measure statistical difference in knowledge and practice of caregivers $(\mathrm{p}<0.05)$ preand post-intervention.

\subsection{Ethical Issues}

Ethical approval was obtained from the University of Ibadan/University College Hospital Ethics Committee. Permission was also received from the Ministry of Women Affairs, Oyo state and Association of Orphans and Vulnerable children, Oyo State chapter. Also, the head of each orphanage gave informed consent after researchers explained the purpose of the research. All information was handled with confidentiality.

\section{Results}

Socio-demographic characteristics of caregivers are summarized in (Table 1). A total of 50 participants were enrolled in the study. Majority $(80 \%)$ of the respondents were females and very few (10\%) of them were older than 50 years while $60 \%$ were between the ages 21 - 30 years. A little above half (54\%) had secondary school education. Those that had worked between $1-5$ years were $48 \%$ whereas only $22 \%$ had worked for more than 10 years.

Table 1. Socio-demographic characteristics of orphanage caregivers.

\begin{tabular}{lcc}
\hline & \multicolumn{2}{c}{ Socio-demographic Characteristics } \\
\cline { 2 - 3 } & Frequency & Percentage \\
\hline Sex & 10 & 20 \\
Male & 40 & 80 \\
Female & & \\
Age (in years) & 30 & 60 \\
21 - 30 & 11 & 22 \\
31 - 40 & 4 & 8 \\
41 - 50 & 5 & 10 \\
Above 50 & & \\
Marital Status & 23 & 46 \\
Single & 24 & 48 \\
Married & 1 & 2 \\
Widowed & & 54 \\
Educational Status & 5 & 10 \\
Primary & 27 & 56 \\
Secondary & 58 & \\
Tertiary & & \\
\hline
\end{tabular}


Table 2 provides data on caregivers' knowledge on complementary feeding. At baseline, some of the caregivers correctly answered, "time to introduce water to an infant after birth" (84\%), "use of locally available foods as complementary foods" (72\%), and "time of introduction of solid, semi-solid and soft food to a child" (84\%) and these increased at post-intervention to $87.5 \%, 91.7 \%, 91.7 \%$ respectively. Caregivers' knowledge with respect to enrichment of pap with oil at different age groups (6 - 8 months (60\%), 9 - 11 months (62\%), 12 - 24 months (64\%) and change in child food intake (78\%) were above average at baseline. At immediate post-intervention, there was an improvement which was sustained at 2 weeks post-intervention.

Table 2. Caregiver's knowledge on complementary feeding.

\begin{tabular}{|c|c|c|c|}
\hline & \multicolumn{3}{|c|}{ Pre- and Post-Knowledge assessment } \\
\hline & Baseline (\%) & $\begin{array}{l}\text { Post intervention } \\
\text { (\%) }\end{array}$ & $\begin{array}{c}\text { After } 2 \\
\text { weeks (\%) }\end{array}$ \\
\hline $\begin{array}{l}\text { Introduction of water to a child should } \\
\text { be after birth }\end{array}$ & $42(84)$ & $17(65.4)$ & $21(87.5)$ \\
\hline $\begin{array}{l}\text { Importance of breast milk immediately } \\
\text { after birth }\end{array}$ & $40(80)$ & $24(92.3)$ & $24(100)$ \\
\hline $\begin{array}{l}\text { Use of locally available foods as } \\
\text { complementary food }\end{array}$ & $36(72)$ & $24(92.3)$ & $22(91.7)$ \\
\hline $\begin{array}{l}\text { Introduction of solid, semi-solid and soft } \\
\text { foods should start at } 6 \text { months }\end{array}$ & $42(84)$ & $24(92.3)$ & $22(91.7)$ \\
\hline Increase food intake as the child gets older & $39(78)$ & $25(96.2)$ & 23(95.8) \\
\hline $\begin{array}{l}\text { Texture of food changes as child } \\
\text { grows older }\end{array}$ & $46(92)$ & $26(100)$ & $24(100)$ \\
\hline $\begin{array}{l}\text { Addition of soybean powder to a } \\
6 \text { - 8-month-old food }\end{array}$ & $45(90)$ & $24(92.3)$ & $24(100)$ \\
\hline $\begin{array}{l}\text { Addition of soybean powder to a } \\
9 \text { - 11-month-old food }\end{array}$ & $47(94)$ & $24(92.3)$ & $24(100)$ \\
\hline $\begin{array}{l}\text { Addition of soybean powder to a } \\
12 \text { - 24-month-old food }\end{array}$ & $46(92)$ & $24(92.3)$ & $24(100)$ \\
\hline $\begin{array}{l}\text { Blended crayfish can be added to the } \\
\text { food of a } 6-8 \text { month }\end{array}$ & $48(96)$ & $23(88.5)$ & $24(100)$ \\
\hline $\begin{array}{l}\text { Blended crayfish can be added to the } \\
\text { food of a } 9-11 \text { month }\end{array}$ & $45(90)$ & $23(88.5)$ & $24(100)$ \\
\hline $\begin{array}{l}\text { Blended crayfish can be added to the } \\
\text { food of a } 12-24 \text { month }\end{array}$ & $47(94)$ & $23(88.5)$ & $24(100)$ \\
\hline $\begin{array}{l}\text { Enrich pap with oil for a } 6 \text { - 8-month-old } \\
\text { child }\end{array}$ & $30(60)$ & $18(69.2)$ & $16(66.7)$ \\
\hline $\begin{array}{l}\text { Enrich pap with oil for a } 9 \text { - 11-month-old } \\
\text { child }\end{array}$ & $31(62)$ & $18(69.2)$ & $20(83.3)$ \\
\hline $\begin{array}{l}\text { Enrich pap with oil for a } 12 \text { - 24-month-old } \\
\text { child }\end{array}$ & $32(64)$ & $20(76.9)$ & $19(79.2)$ \\
\hline
\end{tabular}


As shown in Table 3, there was an increase (62.5\%) in the feeding frequency of the children after intervention. The minimum dietary diversity (MDD) and minimum adequate diet $(\mathrm{MAD})$ also increased respectively. There was a significant increase in the frequency of feeding among children between $12-24$ months before (12.5\%) and after (35\%) intervention. There was also a slight increase among other age groups. There was a significant difference $(\mathrm{p}<0.000)$ between MMF, MDD, MAD at baseline and post-intervention which cut across all the age group and WHO indicators. Knowledge of the caregivers was observed to have improved with the intervention (Figure 1). This improvement marginally decreased after two weeks.

Table 3. ${ }^{\mathrm{a}}$ Feeding practices of caregivers based on selected WHO-IYCF ${ }^{\mathrm{b}}$ indicators.

\begin{tabular}{|c|c|c|c|c|c|c|c|c|c|}
\hline \multirow{3}{*}{ Indicators } & \multicolumn{4}{|c|}{ Baseline } & \multicolumn{4}{|c|}{ Post Intervention } & \multirow{3}{*}{$\mathrm{p}$-value } \\
\hline & $6-8$ & $9-11$ & $12-24$ & $6-24$ & $6-8$ & $9-11$ & $12-24$ & $6-24$ & \\
\hline & N (\%) & N (\%) & N (\%) & N (\%) & N (\%) & N (\%) & N (\%) & N (\%) & \\
\hline \multicolumn{10}{|l|}{${ }^{\mathrm{c}} \mathrm{MMF}$} \\
\hline Met & $3(7.5)$ & $7(17.5)$ & $5(12.5)$ & $15(37.5)$ & $3(7.5)$ & $7(17.5)$ & $14(35.0)$ & $25(62.5)$ & 0.001 \\
\hline Not Met & $3(7.5)$ & $3(7.5)$ & $15(47.5)$ & $25(62.5)$ & $3(7.5)$ & $3(7.5)$ & $10(25.0)$ & $15(37.5)$ & \\
\hline Total & $6(15.0)$ & $10(25.0)$ & $25(60.0)$ & $40(100.0)$ & $6(15.0)$ & $10(25)$. & $24(60.0)$ & $40(100)$ & \\
\hline \multicolumn{10}{|l|}{${ }^{\mathrm{d}} \mathrm{MDD}$} \\
\hline Met & $5(12.5)$ & $9(22.5)$ & $7(17.4)$ & $21(52.5)$ & $5(12.5)$ & $9(22.5)$ & $18(45)$ & $32(80)$ & 0.001 \\
\hline Not Met & $1(1.2)$ & $1(1.2)$ & $17(20.2)$ & $19(47.5)$ & $1(2.5)$ & $1(2.5)$ & $6(15)$ & $8(20)$ & \\
\hline Total & $6(13.7)$ & $10(23.7)$ & $24(37.6)$ & $40(100.0)$ & $6(15.0)$ & $10(25)$. & $24(60.0)$ & $40(100)$ & \\
\hline \multicolumn{10}{|l|}{${ }^{\mathrm{e}} \mathrm{MAD}$} \\
\hline Met & $3(7.5)$ & $7(10.0)$ & $4(17.5)$ & $11(35)$ & $4(12.5)$ & $7(10.0)$ & $13(20)$ & $24(60.0)$ & 0.001 \\
\hline Not Met & $3(7.5)$ & $3(15.0)$ & $20(42.5)$ & $29(65.0)$ & $2(2.5)$ & $3(14.5)$ & $11(40.0)$ & $16(40.0)$ & \\
\hline Total & $6(15.0)$ & $10(25.0)$ & $24(60.0)$ & $40(100.0)$ & $6(15.0)$ & $10(24.5$ & $24(60.0)$ & $40(100)$ & \\
\hline
\end{tabular}

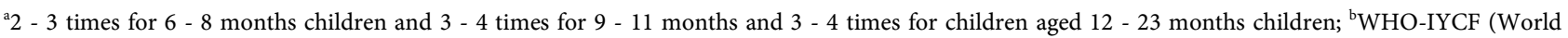
Health Organization-Infant and Young Child Feeding); ${ }^{\mathrm{c}} \mathrm{MMF}$ (Minimum meal Frequency); ${ }^{\mathrm{d}}$ MDD (Minimum Dietary Diversity); ${ }^{\mathrm{e}} \mathrm{MAD}$ (Minimum Acceptable Diet).

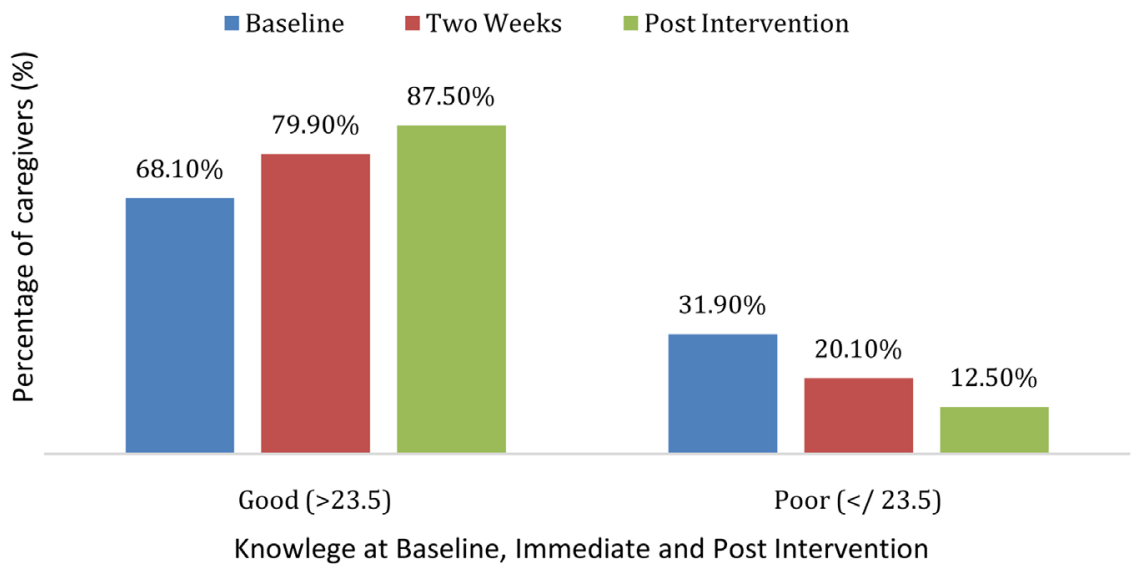

Figure 1. Chart showing the overall percentage knowledge at baseline, immediate post and two weeks post intervention. 


\section{Discussion}

Caregivers have been viewed as proxy parental figures by some authors [15], which position the caregivers as crucial to an orphaned child's life. The findings of this study indicated that most of the caregivers had at least high school education. This was reflected in a study [16] where direct caregivers have fewer years of education and lack training in child development which results in deficiency in childcare. It was reported by another study [17] that caregiver's education and child related training are necessary components for the quality of childcare.

Furthermore, the present study recorded that majority of the caregivers had good knowledge about consistency of food as a child grows older which may directly or indirectly inform the appropriate feeding of a child. Majority had poor knowledge about the use of feeding bottle and frequency of feeding for a breastfed and non-breastfed child which could result in malnutrition among children within the age bracket (6 - 24 months). This is similar to the reports of [3] [10]. In the present study, the significant difference $(p<0.05)$ recorded between caregiver's complementary feeding knowledge at baseline and post-intervention implied that nutrition education on complementary feeding could facilitate effective care of the children.

Similar studies [10] [18] [20] have reported that nutrition education for caregivers improved their infant and young child feeding practice. For instance, an intervention study in Eastern Ethiopia [18] that assessed the effect of nutrition education on the caregiver's knowledge and practice, found out significant improvement in the practice of the caregivers. In addition, [10] [19] reported significant improvement in the caregivers/mothers' knowledge after nutrition education. Similarly, an intervention study that trained community health workers [20] also found out that there was an improvement in their knowledge, attitude and practice after nutrition intervention. A significant relationship between complementary feeding practice pre and post intervention was obtained in the present study. Therefore, the percentage of caregivers that engaged in appropriate complementary feeding practice increased following the nutrition education intervention. These findings are comparable to a study carried out in Kenya where mothers with high complementary feeding knowledge achieved the recommended minimum meal frequency, dietary diversity and acceptable diet after the nutrition education intervention [21]. In addition, another study in Ethiopia found out that caregivers'/mothers' knowledge on complementary feeding influenced minimum dietary diversity [22].

Our study has a few limitations. First, it was carried out among selected caregivers thus the inability to generalize to other settings. They were selected caregivers because not all orphanage homes have children of this age range. The short duration of training for caregivers is also a possible limitation while this study did not have a control group.

\section{Conclusion}

This study showed that nutrition education on complementary feeding did lead 
to improved knowledge and practice of caregivers in orphanage homes. With the increase in knowledge, there was an increase in practice. Hence, nutrition education intervention can successfully improve complementary feeding knowledge and practice which may translate to improved child nutrition especially among vulnerable group. It will be prudent of the government and major stakeholders to invest in a constant training of orphanage caregivers. This will help to continually strengthen and sustain their knowledge and practice which should contribute to improved health and wellbeing of these vulnerable groups. This will be achieved by designing nutrition education programs for caregivers. It should however be noted that nutrition education actions are most effective when are accompanied by policies and actions to support changes in children's food environment, rather than mere information provision or direct education alone.

\section{Acknowledgements}

We would like to express our gratitude to the Association of Orphans and vulnerable children, Oyo state chapter and Ministry of women Affairs, Oyo state for their generous support in this research investigation.

\section{Conflicts of Interest}

The authors declare no conflicts of interest regarding the publication of this paper.

\section{References}

[1] World Health Organization (2009) Global Data Bank on Infant and Young Child Feeding. World Health Organization, Geneva.

[2] Kavitha, S., Nadhiya, C. and Parimalavalli, R. (2014) Study of Complementary Feeding Practices among Mothers of Infants Aged Six Months to One Year. Healthline, 5, 29-35.

[3] Lodha, S. and Bharti, V. (2013) Assessment of Complementary Feeding Practices and Misconceptions Regarding Foods in Young Mothers. International Journal of Food and Nutritional Sciences, 2, 85-90.

[4] United Nations International Children Emergency Fund (2013) Statistical Snapshot: Child Mortality. UNICEF Data and Analytics, Division of Policy and Strategy. United Nations International Children Emergency Fund, New York.

[5] Edemba, C.L. (2014) Biochemical Assessment of Zinc Status of Under-Five Children in Orphanages of Federal Capital Territory, Abuja, Nigeria. Journal of Dental and Medical Sciences, 13, 60-70.

[6] National Population Commission (NPC) Nigeria and International Coaching Federation (ICF) (2019) Nigeria Demographic and Health Survey 2018. National Population Commission (NPC) Nigeria and International Coaching Federation (ICF), Abuja and Rockville.

[7] Shukla, B. and Shukla, D. (2011) Study to Assess Physical Health Status of Children at Selected Orphanage in Salem Chennai India. International Research Journal, 1, 3-8. https://doi.org/10.51611/iars.irj.v1i2.2011.10

[8] Vaida, N. (2013) Nutritional Status of Children Living in Orphanages in District 
Budgam J and K. International Journal of Humanistic and Social Science Invention, 2, 36-41.

[9] Kulwa, K.B., Verstraeten, R., Bouckaert, K.P., Mamiro, P.S., Kolsteren, P.W. and Lachat, C. (2014) Effectiveness of a Nutrition Education Package in Improving Feeding Practices, Dietary Adequacy and Growth of Infants and Young Children in Rural Tanzania: Rationale, Design and Methods of a Cluster Randomized Trial. BMC Public Health, 14, Article No. 1077.

https://doi.org/10.1186/1471-2458-14-1077

[10] Manikyamba, D., Vidya, D.L., Satyavani, A., Krishna Prasad, A. and Tulasi Deepthi, K. (2015) Impact of Nutritional Education on the Knowledge of Mothers Regarding Infant and Young Child Feeding Practices. Scholars Journal of Applied Medical Sciences, 3, 1074-1078.

[11] Eke, B.C., Edelu, B.O., Ukoha, O.M. and Ikefuna, A.N. (2014) Nutritional Status of Children Living in Motherless Babies' Homes in Enugu State Southeast Nigeria. Indian Journal of Applied Research, 4, 478-482. https://doi.org/10.15373/2249555X/August2014/124

[12] Obiakor-Okeke, N. and Nnadi, C. (2014) Nutritional Status, Care Giving and Feeding Practices of Infant and Pre-School Children (0-5 Years) in Motherless Babies Homes in Owerri Metropolis. Journal of Biology, Agriculture and Healthcare, 4, 190-198.

[13] Marías, Y.F. and Glasauer, P. (2014) Guidelines for Assessing Nutrition-Related Knowledge, Attitudes and Practices. Food and Agriculture Organization of the United Nations (FAO), Rome.

[14] Federal Ministry of Health (2013) National Counselling Cards on Infant and Young Child Feeding for Community Health Workers. Federal Ministry of Health, Abuja. https://www.unicef.org/nutrition/files/Nigeria_c-iycf_counselling_cards.pdf

[15] Smyke, A.T., Koga, S.F., Johnson, D.E., Fox, N.A., Marshall, P.J., Nelson, C.A., Zeanah, C.H. and BEIP Core Group (2007) The Caregiving Context in Institution-Reared and Family Reared Infants and Toddlers in Romania. Journal of Child Psychology and Psychiatry, 48, 210-218. https://doi.org/10.1111/j.1469-7610.2006.01694.x

[16] Vashchenko, M., Easterbrooks, A. and Miller, L.C. (2010) Becoming Their Mother: Knowledge, Attitude and Practice of Orphanage Personnelin Ukraine. Infant Mental Health Journal, 31, 570-590. https://doi.org/10.1002/imhj.20272

[17] Bradley, R.H. and Vandell, D.L. (2007) Childcare and the Well-Being of Children. Archives of Pediatrics and Adolescent Medicine, 161, 669-676. https://doi.org/10.1001/archpedi.161.7.669

[18] Guled, R.A., Nik, M.M., Tefera, B., Wan Azdie, M.A.B. and Nega, A. (2018) Effect of Nutrition Education Intervention on Knowledge Attitude and Practice of Mothers/Caregivers on Infant and Young Child Feeding in Shabelle (Gode) Zone, Somali Region, Eastern Ethiopia. Revelation and Science, 8, 50-59.

[19] Samuel, F.O., Olaolorun, F.M. and Adeniyi, J.D. (2016) A Training Intervention on Child Feeding among Primary Healthcare Workers in Ibadan Municipality. African Journal of Primary Health Care and Family Medicine, 8, Article No. a884. https://doi.org/10.4102/phcfm.v8i1.884

[20] Sukandar, D., Khomsan, A., Anwar, F., Riyadi, H. and Mudjajanto, E.S. (2015) Nutrition Knowledge, Attitude, and Practice of Mothers and Children Nutritional Status Improved after Five Months Nutrition Education Intervention. International Journal of Science: Basic and Applied Research, 23, 424-442. 
[21] Maingi, M., Kimiywe, J. and Iron-Segev, S. (2020) Maternal Knowledge in Complementary Feeding Following Baby Friendly Community Initiative in Koibatek, Kenya. Maternal \& Child Nutrition, 16, e13027.

https://doi.org/10.1111/mcn.13027

[22] Solomon, D., Aderaw, Z. and Tegene, T.K. (2017) Minimum Dietary Diversity and Associated Factors among Children Aged 6-23 Months in Addis Ababa, Ethipia. International Journal for Equity in Health, 16, Article No. 181.

https://doi.org/10.1186/s12939-017-0680-1 